\title{
Determinants of Lung Bacterial Clearance in Normal Mice
}

\author{
Stephen J. Jay, Waldemar G. Johanson, Jr., \\ Alan K. Pierce, and Joan S. Reisch \\ From the Pauline and Adolph Weinberger Laboratory for Cardiopulmonary \\ Research, Departments of Internal Medicine and Medical Computer Science, \\ The University of Texas Southwestern Medical School at Dallas, \\ Dallas, Texas 75235
}

A в S T R A C T The determinants of the lung clearance of Streptococcus pneumoniae, Klebsiella pneumoniae, Escherichia coli, and Staphylococcus aureus were studied in normal mice after exposure to an aerosol of viable bacteria and ${ }^{90 \mathrm{~m}} \mathrm{Tc}$-labeled dead bacteria. The fraction of bacteria in the lungs that remained viable $4 \mathrm{~h}$ after exposure were: S. pneumoniae, $7.3 \% ; K$. pneumoniae, $121 \%$; E. coli, $88.5 \%$; S. aureus, $27.6 \%$. The rate of physical removal of bacterial particles $\left(k_{m c}\right)$ was determined from the change in lung ${ }^{\circledR \mathrm{m}} \mathrm{Tc}$ counts with time: $k_{m}$ ranged between 7 and 12\%/h and was similar in all species. The rate of mucociliary clearance and of intrapulmonary bacterial killing $\left(k_{k}+k_{m c}\right)$ was calculated from the change in bacterial counts with time in animals that had received tetracycline to inhibit bacterial multiplication. $k_{k}$, the rate of intrapulmonary killing, was obtained by subtraction of $k_{m c}$ from $\left(k_{k}+k_{m c}\right)$. The calculated values for $k_{k}$ were: $S$. pneumoniae, $-87 \% / \mathrm{h} ; K$. pneumoniae, $-17 \% / \mathrm{h} ; E$. coli, $-18 \% / \mathrm{h} ; S$. aureus, $-22 \% / \mathrm{h}$. The rate of intrapulmonary bacterial multiplication $\left(k_{0}\right)$ was estimated from the relationship of bacterial counts in tetracycline and nontetracycline-treated animals, assuming that tetracycline altered only $k_{g}$. $k_{g}$, expressed as the doubling time, was: $S$. pneumoniae, $310 \mathrm{~min}$; $K$. pneumoniae, 217 min ; E. coli, $212 \mathrm{~min}$; S. aureus, $\infty$ (no multiplication). The data indicate that the marked differences in the clearance of these species from the normal mouse lung result from the interaction of differing rates of in vivo bacterial multiplication and killing.

\section{INTRODUCTION}

Pulmonary antibacterial defense mechanisms can be quantitated in experimental animals with an aerosol ex-

Dr. Jay was a Postdoctoral Research Fellow supported by National Heart and Lung Institute training grant $\mathrm{HL}$ 05812 and by the American Lung Association. Dr. Johanson held a U. S. Public Health Service Research Career Development Award HL 70067 during this study.

Received for publication 28 June 1974 and in revised form 15 December 1975.

The Journal of Clinical Investigation

Volume 57 posure technique (1). It is generally believed that the decrease with time in the number of viable bacteria remaining in the lung after exposure to a bacterial aerosol is due both to physical removal of bacteria by the mucociliary system and to in situ bacterial killing. Since studies utilizing aerosols of radioactively labeled $\left({ }^{32} \mathrm{P}\right)$ bacteria have shown that viable bacterial counts decreased with time far more rapidly than ${ }^{32} \mathrm{P}$ counts, it is apparent that physical removal plays a minor role (2). In a recent study we found that a third factor, the rate of bacterial multiplication in vivo, was an important determinant of the "lung bacterial clearance" of Streptococcus pneumoniae (3). Thus, the clearance of that organism from the lung was determined by the interaction of mucociliary clearance, in situ killing, and bacterial multiplication.

Differences in lung bacterial clearance among various bacterial species and among different strains of the same species have been noted in normal animals by several investigators $(2,4-6)$. Differing rates of phagocytosis or of intracellular killing of ingested bacteria by alveolar macrophages have been postulated to explain these differences (4). It may be that differing ability of bacteria to multiply in the lung explains part of this difference.

The present investigation was undertaken to examine the role of bacterial multiplication in the lung clearance of several bacterial species implicated in pneumonia. Our results indicate inter- and intraspecies differences in both the in vivo rates of bacterial multiplication and bacterial killing.

\section{METHODS}

Organisms. The strain of $S$. pneumoniae type 3 used in these studies has been maintained in our laboratory for several years with weekly transfers on blood agar plates and periodic passages through mice. Tetracycline-susceptible strains of Staphylococcus aureus, Klebsiella pneumoniae, and Escherichia coli were obtained from clinical isolates. Attempts to induce tetracycline resistance in these susceptible strains were unsuccessful, necessitating the selection of 
tetracycline-resistant strains from additional clinical isolates. A tetracycline-resistant strain of $S$. preumoniae type 3 could not be obtained. Susceptibility of all strains to tetracycline was determined both by a disk technique (7) and by determining the organism's growth rate in broths containing tetracycline at concentrations of $0.5,1.0,5.0,10.0$, and $20.0 \mu \mathrm{g} / \mathrm{ml}$ and in control broths (3). Broth cultures of $S$. pneumoniae were grown in Todd-Hewitt broth; other species were grown in trypticase soy broth. For aerosol exposure studies, 1.0-liter broth cultures were incubated overnight, centrifuged, and washed. One-half of the sediment was labeled with technetium $\left({ }^{00 \mathrm{~m}} \mathrm{Tc}\right)(8)$. This labeling procedure renders the labeled bacteria nonviable but does not alter their aerodynamic properties. The ${ }^{00 \mathrm{~m}} \mathrm{Tc}$-labeled, nonviable bacteria and the nonlabeled, viable bacteria were mixed and resuspended in normal saline for aerosolization.

Since our initial results indicated that the clearance of ${ }^{80 \mathrm{~m}} \mathrm{Tc}$ from the mouse lung exceeded the reported clearance of other isotopes, two studies were performed with $S$. aureus labeled with ${ }^{\circ} \mathrm{P}(9)$. In one of these studies $S$. aureus grown in ${ }^{39} \mathrm{P}$ overnight was further subjected to the ${ }^{00 m} \mathrm{Tc}-$ labeling procedure but without the addition of ${ }^{00 m} \mathrm{Tc}$. In the other study the ${ }^{2} \mathrm{P}$-labeled $S$. aureus was only centrifuged and washed (9). The dissociation of ${ }^{{ }^{0 m} \mathrm{~m}} \mathrm{Tc}$ in saline suspensions of labeled organisms was studied over a 4-h period by repeated centrifugation and sampling of the supernate.

Aerosol exposure. In each study, 66 white Swiss mice weighing 20-22 $\mathrm{g}$ were exposed for $30 \mathrm{~min}$ in a modified Henderson exposure chamber utilizing a Collison nebulizer (10). One-half of the animals were injected intraperitoneally with tetracycline, $50 \mathrm{mg} / \mathrm{kg}$ in saline, immediately before exposure; the remaining animals were injected with comparable volumes of sterile saline. Changes in the serum concentrations of tetracycline with time were determined in similarly injected mice not exposed to a bacterial aerosol by the technique of Simon and Yin (11).

The aerosol was sampled in midrun with glass impingers and an Andersen sampler incorporating a $10 \%$ gelatin medium on each of the six stages. The concentration of viable bacteria in the impinger sample was determined by serial 10 -fold dilutions, and the radioactivity in a $1.0-\mathrm{ml}$ portion was determined in a well counter. ${ }^{1}$ The Andersen stages were melted at $40^{\circ} \mathrm{C}$, and quantitative bacterial and radioactive counts were determined in similar fashion.

At the termination of the 30-min aerosol exposure $(0 \mathrm{~h})$, one-fourth of both the tetracycline-injected and saline-injected mice were sacrificed by cervical subluxation and cross-clamping of the neck to prevent agonal aspiration of oropharyngeal contents. The lungs were aseptically removed and homogenized in sterile water, and serial 10-fold dilutions were inoculated on appropriate media for bacteriologic culture. The remainder of the lung homogenate was transferred to a plastic tube for radioactive counting. Approximately equal numbers of animals from the tetracycline and saline groups were sacrificed at 1,2 , and $4 \mathrm{~h}$ after exposure and handled similarly. In the two studies using ${ }^{\circ} \mathrm{P}$, radioactivity in the aerosol and in the lungs was determined by the technique of Green and Green (12).

Analysis of results. Counts of radioactivity and the number of viable bacteria were corrected for dilution and expressed as counts per both lungs. To correct the ${ }^{00 m} \mathrm{Tc}$ counts for decay during the counting procedure, all counts were extrapolated to a single time.

\footnotetext{
${ }^{1}$ Packard series 5000 Auto-gamma spectrometer, Packard Instrument Co., Inc., Downers Grove, Ill.
}

In our previous analysis (3), we assumed that net lung bacterial clearance was determined by two rate constants: $k_{1}$ represented the rate of bacterial multiplication; $k_{2}$ represented the combined rates of physical removal and killing of bacteria deposited in the lung. In the present study three rate constants are calculated. We assume that the rate of disappearance of radioactivity from the lungs is due to physical removal of particles by mucocilliary clearance and that viable and nonviable particles are removed from the lungs similarly; we have designated this rate constant $k_{\text {mo. }}{ }^{2}$ We have designated the rate of intrapulmonary bacterial multiplication as $k_{0}$ and the rate of bacterial killing in the lung as $k_{k}$. Thus, in control animals :

$$
C_{t}=C_{0} e^{-\left(k_{m c}+k_{k}-k_{g}\right) t}
$$

where $C_{t}$ is the concentration of bacteria in the lungs at time $t ; C_{0}$ is the concentration of bacteria in the lungs at time $0 ; k_{m o}$ is the rate of physical removal of particles; $k_{k}$ is the rate of intrapulmonary bacterial killing; and $k_{0}$ is the rate of bacterial multiplication.

In animals treated with tetracycline we assume that $k_{g}$ $=0$. Therefore:

$$
C_{t_{e t} t_{t}}=C_{t e t_{0}} e^{-\left(k_{m c}+k_{k}\right) t}
$$

where $C_{t^{*} t_{t}}$ is the concentration of bacteria in the lungs of tetracycline-treated animals at time $t$, and $C_{\text {tot }_{0}}$ is the concentration of bacteria in the lungs of tetracycline-treated animals at time 0 .

Thus, $\left(k_{m o}+k_{k}\right)$ was determined by calculating the slope of the disappearance of viable bacteria (expressed as ratios and converted to natural logarithms) with time from the lungs of tetracycline-treated mice. $k_{m o}$ was determined by calculating the slope of the disappearance of ${ }^{80 \mathrm{~m}} \mathrm{Tc}$ counts (converted to natural logarithms) with time from the lungs of tetracycline-treated mice. The rate of bacterial killing $k_{k}$ was obtained by subtracting the $k_{m o}$ from $k_{m o}$ $+k_{k}$ of tetracycline-treated animals for each species.

An estimate of the rate of bacterial multiplication in vivo over an interval of time, $\Delta t$, can be obtained by solving the equation given below for $k_{0}$ after substitution and division of (1) by (2):

$$
\frac{C_{t_{\text {(time 2) }}}}{C_{\text {tet }_{(\text {time } 2)}}}=\frac{C_{t_{(\text {time 1) }}}}{C_{\text {tet }_{\text {(time 1) }}}} e^{k_{g}(\Delta t)}
$$

To avoid a period of lag phase growth which may follow aerosolization (3), we used the changes in bacterial concentration between 2 and $4 \mathrm{~h}$ in the lungs of control and tetracycline-treated animals to calculate $k_{g}$. That is:

$$
\frac{C_{t_{(4 \mathrm{~h})}}}{C_{t e t_{(4 \mathrm{~h})}}}=\frac{C_{t_{(2 \mathrm{~h})}}}{C_{t e t_{(2 \mathrm{~h})}}} e^{(2) k_{g}}
$$

The concentration of bacteria initially deposited in the lungs varied from study to study, depending on slurry concentration, viability of the aerosolized bacteria, and the

Abbreviations used in this paper: $k_{g}$, rate of intrapulmonary bacterial multiplication; $k_{k}$, rate of intrapulmonary bacterial killing; $k_{m o}$, rate of physical removal of bacterial particles; $R$, ratio of the number of viable bacteria in the lungs of each animal to the mean number of bacteria initially deposited. 
TABLE I

Clearance of Tetracycline-Susceptible Strains

\begin{tabular}{|c|c|c|c|c|c|}
\hline & \multirow{2}{*}{$\begin{array}{c}\text { Total } \\
\text { animals }\end{array}$} & \multirow{2}{*}{$\begin{array}{l}\text { Mean number of } \\
\text { bacteria deposited* }\end{array}$} & \multicolumn{3}{|c|}{$R$ values } \\
\hline & & & $1 \mathrm{~h}$ & $2 \mathrm{~h}$ & $4 \mathrm{~h}$ \\
\hline \multicolumn{6}{|l|}{ S. pneumoniae } \\
\hline Saline & 92 & $4,766 \pm 639(24)$ & $0.284 \pm 0.089$ & $0.201 \pm 0.081$ & $0.073 \pm 0.032$ \\
\hline Tetracycline & 87 & $4,119 \pm 473$ & $0.127 \pm 0.037(17)$ & $0.023 \pm 0.009(23) \S$ & $0.006 \pm 0.004(24) \S$ \\
\hline \multicolumn{6}{|l|}{$K$. pneumoniae } \\
\hline Saline & 95 & $65,457 \pm 9,548(24)$ & $1.059 \pm 0.088$ & $1.110 \pm 0.111(24)$ & $1.212 \pm 0.102(23)$ \\
\hline Tetracycline & 95 & $59,064 \pm 8,660$ & $0.725 \pm 0.073(24) \S$ & $0.705 \pm 0.068(23) \S$ & $0.525 \pm 0.103(24) \S$ \\
\hline \multicolumn{6}{|l|}{ E. coli } \\
\hline Saline & 126 & $444,283 \pm 41,913(32)$ & $0.846 \pm 0.052$ & $0.914 \pm 0.100$ & $0.885 \pm 0.142$ \\
\hline Tetracycline & 122 & $426,243 \pm 36,468$ & $0.686 \pm 0.035(27) \S$ & $0.572 \pm 0.042(32) \S$ & $0.374 \pm 0.047(31) \S$ \\
\hline \multicolumn{6}{|l|}{ S. aureus } \\
\hline Saline & 140 & $161,398 \pm 15,408$ & $0.592 \pm 0.063$ & $0.454 \pm 0.044$ & $0.276 \pm 0.031$ \\
\hline Tetracycline & 156 & $110,171 \pm 10,540(40) \S$ & $0.772 \pm 0.078$ & $0.615 \pm 0.078$ & $0.366 \pm 0.050(40)$ \\
\hline
\end{tabular}

* Mean \pm SE (sample size).

$\ddagger R=$ the number of viable bacteria in the lungs of each animal/the mean number of bacteria initially deposited.

$\S$ Significantly different from the saline group $(P<0.05)$.

breathing pattern of the animals. The fractional rate of bacterial clearance from the lungs is independent of bacterial concentration over the range encountered in this study (13). To permit the grouping of similar animals from more than one study, we adjusted the lung bacterial counts as follows: the mean lung bacterial count at $0 \mathrm{~h}$ was determined for each group of saline and tetracycline-injected animals each study day. The lung bacterial count for each animal is expressed as a ratio $(R)$ calculated for each animal sacrificed subsequently during that study where: $R$ was observed bacterial count for each animal/mean $0-h$ bacterial count, using the 0 - $h$ mean of the corresponding saline or tetracycline group. Results from separate studies were combined by averaging values for $R$ at $0,1,2$, and $4 \mathrm{~h}$. The mean $R$ values at 1,2 , and $4 \mathrm{~h}$ for saline and tetracycline-injected animals were compared by Student's $t$ test for two independent groups. The logarithms of the ratio values, $R$ 's were used in calculating the reported constants. More detailed statistical considerations are indicated in the Appendix.

\section{RESULTS}

Tetracycline-susceptible strains. Compared to the saline-treated control animals, tetracycline administration was associated with a significant reduction in the fraction of viable bacteria remaining in the lungs at $4 \mathrm{~h}$ among animals exposed to aerosols of $S$. pneumoniae, $K$. pneumoniae, and $E$. coli, but not $S$. aureus (Table I).

TABLE II

Determinants of the Net Clearance in Lung Bacterial Counts (Lung Bacterial Clearance)

\begin{tabular}{|c|c|c|c|c|c|}
\hline & $\begin{array}{l}\text { Rate of decrease of } \\
\text { viable bacteria in } \\
\text { tetracycline-treated } \\
\text { mice, } k_{m c}+k_{k}^{*}\end{array}$ & $\begin{array}{c}\text { Rate of decrease } \\
\text { of lung } 99 \mathrm{mT} \mathrm{T} \\
k_{m c^{*}}\end{array}$ & $\begin{array}{l}\text { Rate of intrapul- } \\
\text { monary bacterial } \\
\text { killing, } k_{k}^{*}\end{array}$ & $\begin{array}{l}\text { Rate of intrapul- } \\
\text { monary bacterial } \\
\text { multiplication, } k_{\theta} *\end{array}$ & $\begin{array}{l}\text { Change in } \\
\text { lung bacterial } \\
\text { counts in } \\
4 \mathrm{~h} \text { in } \\
\text { control mice }\end{array}$ \\
\hline S. pneumoniae & $\begin{array}{c}-2.1461 \pm 0.1376 \\
(-88.3 \% / \mathrm{h})\end{array}$ & $\begin{array}{c}-0.1287 \pm 0.0290 \\
(-12.1 \% / \mathrm{h})\end{array}$ & $\begin{array}{c}-2.0175 \\
(-86.7 \% / h)\end{array}$ & $\begin{array}{c}0.1383 \\
(310 \mathrm{~min}) \ddagger\end{array}$ & $-92.3 \%$ \\
\hline$K$. pneumoniae & $\begin{array}{c}-0.2534 \pm 0.0410 \\
(-22.4 \% / \mathrm{h})\end{array}$ & $\begin{array}{c}-0.0694 \pm 0.0314 \\
(-6.7 \% / \mathrm{h})\end{array}$ & $\begin{array}{c}-0.1840 \\
(-16.8 \% / \mathrm{h})\end{array}$ & $\begin{array}{c}0.1913 \\
(217 \mathrm{~min}) \ddagger\end{array}$ & $+26.3 \%$ \\
\hline E. coli & $\begin{array}{c}-0.3011 \pm 0.0259 \\
(-26.0 \% / h)\end{array}$ & $\begin{array}{c}-0.0982 \pm 0.0249 \\
(-9.4 \% / \mathrm{h})\end{array}$ & $\begin{array}{c}-0.2029 \\
(-18.4 \% / \mathrm{h})\end{array}$ & $\begin{array}{l}0.1960 \\
(212 \mathrm{~min}) \ddagger\end{array}$ & $-30.8 \%$ \\
\hline S. aureus & $\begin{array}{c}-0.3456 \pm 0.0362 \\
(-29.2 \% / \mathrm{h})\end{array}$ & $\begin{array}{c}-0.0966 \pm 0.0254 \\
(-9.2 \% / \mathrm{h})\end{array}$ & $\begin{array}{c}-0.2490 \\
(-22.4 \% / \mathrm{h})\end{array}$ & 0 & $-67.5 \%$ \\
\hline
\end{tabular}

* See text for definition.

$\ddagger$ Expressed as doubling time. 
TABLE III

Characteristics of Bacterial Aerosols

\begin{tabular}{|c|c|c|c|}
\hline & \multicolumn{2}{|c|}{ Fraction of particles $<2 \mu \mathrm{m}^{*}$} & \multirow{2}{*}{$\begin{array}{c}\text { In vitro } \\
\text { 9om Tc } \\
\text { dissociation } \\
\text { in } 4 \mathrm{~h}\end{array}$} \\
\hline & $\begin{array}{c}\text { Viable } \\
\text { particles }\end{array}$ & $\begin{array}{c}99 \mathrm{mTc} \\
\text { particles }\end{array}$ & \\
\hline & $\%$ & $\%$ & $\%$ \\
\hline S. pneumoniae & 89 & 97 & 2.89 \\
\hline$K$. pneumoniae & 83 & 93 & 3.19 \\
\hline E. coli & 100 & 91 & 1.97 \\
\hline S. aureus & 99 & 94 & 1.32 \\
\hline
\end{tabular}

* Stages 5 and 6 of the Andersen sampler.

Marked interstrain differences in the net bacterial clearance of these four organisms over $4 \mathrm{~h}$ were present in the animals receiving only saline. $K$. pneumoniae had increased over 0 -h values on the average while only $7.3 \%$ of the 0 -h $S$. pneumoniae remained. The net clearances of $E$. coli and $S$. aureus were intermediate. The calculated determinants of the net bacterial clearance for each species are shown in Table II. The rate of decrease of viable $S$. pneumoniae was significantly more rapid than that of the other species, and this difference was due to more rapid phagocytosis and killing. The rate of mucociliary removal was similar for all species. The differences in net bacterial clearance between the species other than $S$. pneumoniae were explained by differences in their rates of multiplication in vivo; the lack of multiplication by $S$. aureus was responsible for the more rapid net clearance of that species.

The accuracy of the calculated rate of killing, $k_{k}$, depends on the estimate of $k_{\mathrm{mc}}$. The rate of clearance by the mucociliary mechanism varies with the site of deposi- tion of the bacteria within the lung. The site of deposition of each of the bacterial species was likely in the periphery, since most viable and radioactive particles were less than $2 \mu \mathrm{m}$ in size (Table III). Although dissociation of ${ }^{90 \mathrm{~m}} \mathrm{Tc}$ from the bacterial cell and subsequent removal of the isotope by blood flow could cause an apparent increase in $k_{m c}$, we were unable to demonstrate such dissociation in vitro (Table III). To compare our estimate of $k_{m c}$ with that of other investigators, the rates of removal of ${ }^{20 m} \mathrm{Tc}$ and ${ }^{22} \mathrm{P}$ were compared. The disappearance of ${ }^{32} \mathrm{P}$-labeled $S$. aureus from the lungs was less rapid than that of $\mathrm{Tc}$. By the labeling technique employed for ${ }^{20 \mathrm{~m}} \mathrm{Tc}$, the slope of disappearance of ${ }^{20} \mathrm{P}$ was $-0.0459(4.5 \% / \mathrm{h})$, not significantly different from ${ }^{32} \mathrm{P}$ results by other investigators. These data indicate that the ${ }^{9 m}$ Tc-labeling technique does not account for the differences in the rate of clearance of ${ }^{0 \mathrm{~m}} \mathrm{Tc}$ and ${ }^{\mathrm{*}} \mathrm{P}$. Further, the data suggest that viable and nonviable bacteria are cleared by mucociliary system at similar rates. If the ${ }^{39} \mathrm{P}$ rather than the ${ }^{90 \mathrm{~m}} \mathrm{Tc}$ data are used to calculate $k_{k}$, the fractional killing of staphylococci is estimated to be $24 \% / \mathrm{h}$ instead of $22 \% / \mathrm{h}, \mathrm{S}$. pneumoniae $84 \% / \mathrm{h}$ instead of $87 \% / \mathrm{h}, E$. coli $20 \% / \mathrm{h}$ instead of $18 \% / \mathrm{h}$, and $K$. pneumoniae $18 \% / \mathrm{h}$ rather than $17 \% / \mathrm{h}$. Thus, the different estimates of physical removal produce only small changes in the estimate of the rate of bacterial killing and do not alter the major differences observed among the species.

Tetracycline-resistant strains. Tetracycline-resistant strains of $K$. pneumoniae, $E$. coli, and $S$. aureus were found among clinical isolates; each was resistant to 30 $\mu \mathrm{g}$ of tetracycline by the disk technique and demonstrated growth comparable to control in broths containing tetracycline, $10-20 \mu \mathrm{g} / \mathrm{ml}$. The net lung clearance of these strains was not enhanced by the administration of tetra-

TABLE IV

Clearance of Tetracycline-Resistant Strains

\begin{tabular}{|c|c|c|c|c|c|}
\hline & \multirow{2}{*}{$\begin{array}{c}\text { Total } \\
\text { animals }\end{array}$} & \multirow{2}{*}{$\begin{array}{l}\text { Mean number of } \\
\text { bacteria deposited* }\end{array}$} & \multicolumn{3}{|c|}{$R$ valuest } \\
\hline & & & $1 \mathrm{~h}$ & $2 \mathrm{~h}$ & $4 \mathrm{~h}$ \\
\hline \multicolumn{6}{|l|}{ K. pneumoniae } \\
\hline Saline & 122 & $16,050 \pm 1,717(40)$ & $0.743 \pm 0.093(36)$ & $0.557 \pm 0.083$ & $0.254 \pm 0.082(15)$ \\
\hline Tetracycline & 120 & $17,601 \pm 2,287(40)$ & $0.656 \pm 0.095(37)$ & $0.375 \pm 0.057$ & $0.255 \pm 0.065(13)$ \\
\hline \multicolumn{6}{|l|}{ E. coli } \\
\hline Saline & 87 & $798,505 \pm 132,358(25)$ & $0.618 \pm 0.073(24)$ & $0.657 \pm 0.084(17)$ & $0.437 \pm 0.078(21)$ \\
\hline Tetracycline & 81 & $542,710 \pm 82,046(23)$ & $0.812 \pm 0.081(21)$ & $0.848 \pm 0.109(19)$ & $0.382 \pm 0.046(18)$ \\
\hline \multicolumn{6}{|l|}{ S. aureus } \\
\hline Saline & 40 & $145,672 \pm 20,103(16)$ & $0.530 \pm 0.079(8)$ & $0.242 \pm 0.066$ & $0.059 \pm 0.010$ \\
\hline Tetracycline & 38 & $150,152 \pm 25,216(16)$ & $0.517 \pm 0.119(11)$ & $0.135 \pm 0.045$ & $0.079 \pm 0.023(6)$ \\
\hline
\end{tabular}

* Mean \pm SE (sample size).

$\ddagger R$ is the number of viable bacteria in the lungs of each animal/the mean number of bacteria initially deposited. No significant differences between any pair of experiments was found at any time interval. 
cycline (Table IV). The various determinants of net lung clearance could not be calculated since in vivo multiplication was not inhibited by tetracycline, i.e., $k_{\mathbf{g}} \neq 0$. The concentration of tetracycline in the sera of injected animals varied between 5 and $20 \mu \mathrm{g} / \mathrm{ml}$.

\section{DISCUSSION}

The lung clearance of bacteria in mice shows marked intra- and interspecies variability (Table V). Alterations in experimental techniques do not explain these differences, since variability has been observed in the studies in which the clearance of different strains of the same species or of different species was compared (2, $4-6,14,15)$. The determinants of lung clearance are multiple, including physical removal of bacteria, bacterial killing, and bacterial multiplication. Because of the interaction of these factors, we prefer to designate the observed changes in the number of viable bacteria in the lungs of experimental animals after aerosol deposition as "net lung bacterial clearance." In the present study we have estimated the contribution of these determinants to net lung bacterial clearance in order to explain interspecies variability.

The data suggest that physical removal of bacteria from the lung after aerosol deposition was similar for the four bacterial species. Thus, physical removal cannot explain the observed interspecies variability in net lung clearance. This constant rate of physical removal contributed little to the net clearance of the pneumococcus, but was quantitatively more important in the net removal of $K$. pneumoniae, $E$. coli, and $S$. aureus.

Our index of physical removal, the rate of decrease of lung ${ }^{{ }^{m} \mathrm{Tc}} \mathrm{Tc}$ counts, was $9 \% / \mathrm{h}$ for staphylococci while that reported for ${ }^{32} \mathrm{P}$-labeled staphylococci (9) is $4.6 \% / \mathrm{h}$. We have examined these differences in isotope clearance in several ways. In our exposure system, ${ }^{32} \mathrm{P}$-labeled staphylococci are cleared at a rate comparable to that reported by others (9). This clearance rate was not altered when ${ }^{32} \mathrm{P}$-labeled staphylococci were killed during the ${ }^{90 \mathrm{~m}} \mathrm{Tc}$-labeling procedure. Thus, the more rapid clearance of ${ }^{8 \mathrm{~m}} \mathrm{Tc}$ is not explained by the nonviable state of the ${ }^{80 \mathrm{~m}} \mathrm{Tc}$-labeled bacteria. The rate of dissociation of ${ }^{90 \mathrm{~m}} \mathrm{Tc}$ from staphylococci in vitro is less than the $20 \%$ in $4 \mathrm{~h}$ reported for ${ }^{32} \mathrm{P}$-labeled staphylococci (9). A difference in the site of deposition within the lung for bacteria labeled with the two isotopes is unlikely, since ${ }^{32} \mathrm{P}$ labeled bacteria further subjected to the ${ }^{90 \mathrm{~m}} \mathrm{Tc}$-labeling procedure were cleared at rates similar to those with only standard ${ }^{32} \mathrm{P}$-labeling procedures. Further, the size distribution of ${ }^{{ }^{\circ m}} \mathrm{Tc}$-labeled particles is such that peripheral deposition would be expected. Other investigators have compared the lung clearance of bacteria labeled with ${ }^{2} \mathrm{P}$ and ${ }^{35} \mathrm{~S}$ and found similar differences (19). While the

\begin{tabular}{|c|c|c|}
\hline Species & $\begin{array}{c}\text { Fraction } \\
\text { of viable } \\
\text { bacteria } \\
\text { remaining } \\
\text { in the lungs } \\
\text { at } 4 \mathrm{~h}\end{array}$ & Reference \\
\hline & $\%$ & \\
\hline pneumoniae & 1.21 & Present data \\
\hline$P$. aeruginosa (22) & 0.97 & 14 \\
\hline E. coli & 0.89 & Present data \\
\hline P. aeruginosa (OI) & 0.46 & 5 \\
\hline E. coli (tetracycline-resistant) & 0.44 & Present data \\
\hline$P$. aeruginosa (E) & 0.42 & 5 \\
\hline Serratia marcescens (nonpigmented) & 0.35 & 15 \\
\hline$P$. pneumotropica & 0.35 & 16 \\
\hline Proteus mirabilis & 0.29 (mean) & $2,4-6$ \\
\hline S. aureus & 0.28 & Present data \\
\hline Serratia marcescens (pigmented) & 0.26 & 15 \\
\hline K. pneumoniae (tetracycline-resistant) & 0.25 & Present data \\
\hline K. pneumoniae & 0.18 & 17 \\
\hline$P$. aeruginosa (16) & 0.13 & 14 \\
\hline S. aureus & 0.13 (mean) & $2,6,13,18$ \\
\hline Flavobacterium & 0.10 & 5 \\
\hline S. pneumoniae & 0.07 & Present data \\
\hline S. aureus (tetracycline-resistant) & 0.06 & Present data \\
\hline Herellea & 0.03 & 5 \\
\hline S. albus & 0.01 & 4 \\
\hline
\end{tabular}

mechanism of these differences is unclear, our data indicate that differences in the rate of physical removal cannot explain the variability of net lung clearance among the species studied.

Interspecies variability in net lung clearance is due to differences in the apparent rate of bacterial killing and the in vivo rate of bacterial multiplication. We have employed a bacteriostatic antibiotic, tetracycline, to quantitate the contributions of each. The validity of this approach requires that tetracycline neither enhance endogenous clearance mechanisms nor contribute directly to bacterial death. The possibility that tetracycline might enhance clearance mechanisms was examined by comparing the clearance of tetracycline-resistant organisms in animals with and without tetracycline treatment. The failure of tetracycline to alter the rate of lung clearance under these circumstances indicates that the effect of tetracycline is on the susceptible organism and not on host defense mechanisms. Further, the serum concentrations of tetracycline achieved were bacteriostatic in vitro, thus a bactericidal effect of the drug in vivo is unlikely.

The rate of apparent bacterial killing, $k_{k}$, in this model is due to the interaction of extracellular bacterial killing, phagocytosis, and intracellular killing. Extracellular killing of inhaled bacteria is generally considered to be minimal (9). Phagocytosis without bacterial death may account for a significant decrease in the number of viable bacteria recovered if multiple organisms are ingested by 
a single macrophage and if that macrophage remains intact until deposited on the bacteriologic medium, since a single bacterial colony will result (20). It is likely that the susceptibility of various bacterial species to phagocytosis by alveolar macrophages differs, since such differences have been observed in phagocytosis by polymorphonuclear leukocytes (21) and circulating monocytes (22). Moreover, LaForce et al. found that while $S$. aureus and $S$. albus were phagocytosed at similar rates by alveolar macrophages in vitro, there were marked differences in the rates of intracellular killing (23).

On the basis of our data we cannot differentiate the relative contributions of phagocytosis and bacterial killing. However, it is apparent that interspecies variability in net lung bacterial clearance is in large part due to the marked differences in apparent bacterial killing between species.

Bacterial multiplication has been thought not to occur in the normal lung after aerosol exposure, since most of the deposited bacteria are rapidly phagocytosed (24). However, our data indicate that at least some bacterial species do replicate under these conditions. Whether such multiplication represents intra- or extracellular growth cannot be ascertained. If multiplication of only extracellular bacteria occurred, more rapid multiplication rates would be expected for organisms with the slowest rates of phagocytosis (25). This relationship was not found; $S$. pneumoniae demonstrated a rate of multiplication only one-third slower than the other organisms, but the most rapid rate of killing. On the other hand, available data suggest that tetracycline does not enter cells or enters only slowly (26). Thus, the observation that tetracycline does enhance clearance of some susceptible bacterial species suggests that a significant fraction of such species remains extracellular. These findings are consistent with those of previous studies that have shown rapid phagocytosis of inhaled staphylococci. Our inability to enhance the clearance of staphylococci with tetracycline may be the result of the intracellular location of these organisms; however, our data suggest that other species may not be phagocytosed as rapidly.

The present data indicate that differences in lang clearance between various species and strains of bacteria can be defined in terms of in vivo bacterial killing and multiplication. How these parameters are influenced by various lung injuries and disease states and how other parameters relate to the pathogenicity of different bacteria remain to be defined.

\section{ACKNOWLEDGMENTS}

We are indebted to Steve Mays and Kent Dana for providing the computer programming expertise necessary for the data analysis.

This study was supported by U. S. Public Health Service grant HL 14187 (a pulmonary SCOR grant).

\section{APPENDIX}

The slope of the disappearance of bacteria from the lungs of tetracycline-treated mice over the 4-h study period is an estimate of $k_{m o}+k_{k}$. This slope was determined by fitting a least squares regression line to the data. The independent variable was time in hours and the dependent variable was the natural logarithm of the bacteria ratio. The $y$ intercept was set equal to zero.

The slope of the disappearance of ${ }^{90 \mathrm{~m}} \mathrm{Tc}$ counts from the lungs of tetracycline-treated mice over the 4-h study period is an estimate of $k_{m o}$. Least squares methods again were used to determine the slope. The independent variable was time in hours and the dependent variable was the natural logarithm of the technitium count.

The standard errors for $k_{m o}+k_{k}$ and $k_{m o}$ reported in Table II are those determined from the regression analyses.

Distributional aspects of 32 sets of data were investigated. Two variables, $\ln \left({ }^{80 m} \mathrm{Tc}\right.$ counts) and $\ln$ (bacteria ratio), for each of the four bacterial species at each of the four time periods were considered. The assumption of the normal or Gaussian distribution was tested by the Kolmogorov-Smirnov procedure. Significant deviation from normality was found for the natural logs of the bacteria ratios for $S$. pmeumoniae at 2 and $4 \mathrm{~h}$; these were significant at the 0.01 level. All but three of the bacteria counts at $4 \mathrm{~h}$ were zero. For mathematical convenience zero values were arbitrarily set equal to 1 before a ratio was calculated. The natural logarithms of the ${ }^{\infty m} \mathrm{Tc}$ values at the $2-\mathrm{h}$ time period for $S$. aureus also were found to differ significantly from a normal distribution at the 0.05 level. No other sets of data were found to differ significantly from the Gaussian distribution at the 0.05 level. In fact, in 26 of the 32 tests for normality, the associated probability values were 0.20 or greater.

Marked heterogeneity of variance for the different time periods for the natural logarithms of bacteria ratios of $S$. preumoniae was observable. We would caution anyone who would use the slopes and their associated standard errors for comparison between bacterial species to investigate both normality and homogeneity of variance before proceeding with the desired tests.

\section{REFERENCES}

1. Laurenzi, G. A., L. Berman, M. First, and E. H. Kass. 1964. A quantitative study of the deposition and clearance of bacteria in the murine lung. J. Clin. Invest. 43: 759-768.

2. Green, G. M., and E. H. Kass. 1964. The role of the alveolar macrophage in the clearance of bacteria from the lung. J. Exp. Med. 119: 167-176 and plates $6 \& 7$.

3. Johanson, W. G., Jr., S. J. Jay, and A. K. Pierce. 1974. Bacterial growth in vivo: an important determinant of the pulmonary clearance of Diplococcus pneumoniae in rats. J. Clin. Invest. 53: 1320-1325.

4. Green, G. M., and E. H. Kass. 1965. The influence of bacterial species on pulmonary resistance to infection in mice subjected to hypoxia, cold stress, and ethanolic intoxication. Br. J. Exp. Pathol. 46: 360-366.

5. Jackson, A. E., P. M. Southern, A. K. Pierce, B. D. Fallis, and J. P. Sanford. 1967. Pulmonary clearance of gram-negative bacilli. J. Lab. Clin. Med. 69: 833-841.

6. Green, L. H., and G. M. Green. 1968. Differential suppression of pulmonary antibacterial activity as the mechanism of selection of a pathogen in mixed bacterial infection of the lung. Am. Rev. Respir. Dis. 98: 819-824.

7. Bauer, A. W., W. M. M. Kirby, J. C. Sherris, and M. Turck. 1966. Antibiotic susceptibility testing by a stan- 
dardized single disk method. Am. J. Clin. Pathol. 45: 493-496.

8. Johanson, W. G., Jr., M. G. Kennedy, and F. J. Bonte. 1973. Use of technetium ( ${ }^{80 \mathrm{~m}} \mathrm{Tc}$ ) as a bacterial label in lung clearance studies. Appl. Microbiol. 25: 592-594.

9. Green, G. M., and E. Goldstein. 1966. A method for quantitating intrapulmonary bacterial inactivation in individual animals. J. Lab. Clin. Med. 68: 669-677.

10. Southern, P. M., Jr., A. K. Pierce, and J. P. Sanford. 1968. Exposure chamber for 66 mice suitable for use with the Henderson aerosol apparatus. Appl. Microbiol. 16: $540-542$.

11. Simon, H. J., and E. J. Yin. 1970. Microbioassay of antimicrobial agents. Appl. Microbiol. 19: 573-579.

12. Green, L. H., and G. M. Green. 1968. Direct method for determining the viability of a freshly generated mixed bacterial aerosol. Appl. Microbiol. 16: 78-81.

13. Green, G. M., and E. H. Kass. 1964. Factors influencing the clearance of bacteria by the lung. J. Clin. Invest. 43: 769-776.

14. Southern, P. M., Jr., A. K. Pierce, and J. P. Sanford. 1971. Comparison of the pulmonary bactericidal capacity of mice and rats against strains of Pseudomonas aeruginosa. Appl. Microbial. 21: 377-378.

15. Southern, P. M., Jr., A. K. Pierce, and J. P. Sanford. 1971. Clearance of Serratia marcescens from lungs of normal mice. Infect. Immun. 3 : 187-188.

16. Goldstein, E., and G. M. Green. 1967. Alteration of the pathogenicity of Pasteurella pneumotropica for the murine lung caused by changes in pulmonary antibacterial activity. J. Bacteriol. 93: 1651-1656.

17. Ehrlich, R., M. C. Henry, and J. Fenters. 1970. Influence of nitrogen dioxide on resistance to respiratory in- fections. In Inhalation Carcinogenesis. U. S. A. E. C. Symp. Ser. 18: 243-257.

18. Laurenzi, G. A., and J. J. Guarneri. 1966. A study of the mechanisms of pulmonary resistance to infection: the relationship of bacterial clearance to ciliary and alveolar macrophage function. Am. Rev. Respir. Dis. 93: 134 141.

19. Jakab, G. J., and G. M. Green. 1973. Regional defense mechanisms of the guinea pig lung. Am. Rev. Respir. Dis. 107 : 776-783.

20. Braude, A. I., and J. Feltes. 1953. Studies in the destruction of staphylococci by human leukocytes: effect of clumping of intracellular and extracellular bacteria on the results obtained with the agar-plate method. J. Lab. Clin. Med. 42: 289-298.

21. Suter, E. 1956. Interaction between phagocytes and pathogenic microorganisms. Bacteriol. Rev. 20: 94-132.

22. Steigbigel, R. T., L. H. Lambert, Jr., and J. S. Remington. 1974. Phagocytic and bactericidal properties of normal human monocytes. J. Clin. Invest. 53: 131-142.

23. LaForce, F. M., W. J. Kelly, and G. L. Huber. 1973. Inactivation of staphylococci by alveolar macrophages with preliminary observations on the importance of alveolar lining material. Am. Rev. Respir. Dis. 108: 784-790.

24. Levy, P. S., and G. M. Green. 1968. A stochastic model of the bactericidal activity of the lung. J. Theor. Biol. $21: 103-112$.

25. Alexander, J. W., and R. A. Good. 1968. Effect of antibiotics on the bactericidal activity of human leukocytes. J. Lab. Clin. Med. 71: 971-983.

26. Mandell, G. L. 1973. Interaction of intraleukocytic bacteria and antibiotics. J. Clin. Invest. 52: 1673-1679. 